\title{
A FORMAÇÃO UNIVERSITÁRIA NO BRASIL: CONCEPÇÕES E INFLUÊNCIAS
}

\author{
Maria de Fátima de PaUla* \\ Recebido em: 02 de fevereiro de 2008 Aprovado em: 01 de novembro de 2008

\begin{abstract}
* Professora da Faculdade de Educação e do Programa de Pós-Graduação em Educação da Universidade Federal Fluminense, e Coordenadora do Núcleo de Estudos e Pesquisas em Educação Superior da UFF E-mail: mfatimadepaula@terra.com.br
\end{abstract}

Resumo: O texto trata da formação universitária no Brasil, trazendo um breve histórico da universidade no mundo e em nosso país. Aborda as concepções francesa, alemã e norte-americana de universidade e a sua influência sobre o caso brasileiro, trazendo reflexões sobre as políticas para o ensino superior que têm conseqüência sobre o processo de formação. Na parte final, traz um panorama da educação superior no Brasil, no contexto do neoliberalismo, enfocando aspectos críticos relacionados à formação universitária, na atualidade.

Palavras chave: Formação universitária. Brasil. Concepções. Influências.

\section{HIGHER EDUCATION IN BRAZIL: CONCEPTS AND INFLUENCES}

\begin{abstract}
The text discusses Brazilian higher education, with a brief history of the university in the world and in our country. It studies the French, German and North American concepts of University and their influence on the Brazilian model, analyzing the policies for higher education that affect the education process. The last part makes a survey of Brazilian higher education in the context of neo-liberalism, focusing on critical aspects related to undergraduate studies at the present time.
\end{abstract}

Key words: Higher Education. Brazil. Concepts. Influences.

\section{Introdução}

Dando um mergulho na história da existência da universidade, vemos que desde a criação das primeiras universidades, nos séculos XII e XIII, na Idade Média, como a Universidade de Bolonha, criada em 1190, a Universidade de Oxford, fundada em 1214, e a Universidade de Paris, criada em 1215, esta instituição social vem tentando conquistar a sua autonomia, primeiramente, diante do poder da Igreja, pois a universidade medieval se estruturou fundamentalmente como uma corporação sob o controle da Igreja.

A partir do século XV, com a emergência dos Estados nacionais, a universidade passou a ser controlada pelo poder do Estado. A Reforma Protestante cinde a dinâmica da instituição, rompendo com o monopólio da Igreja, mas a 
reação da Contra-Reforma teve uma forte influência, sobretudo na Península Ibérica e em suas colônias.

No final do século XVIII, a universidade iluminista foi sacudida pela Revolução de 1789, anti-universitária por excelência, pois condenou a instituição universitária como sendo um aparato do Antigo Regime, colocando em seu lugar escolas profissionais de ensino superior. Da França e da Prússia emergiram, no início do século XIX, as primeiras universidades modernas e laicas: a napoleônica, para formar quadros para o Estado, e a de Berlim, com ênfase na integração entre ensino e pesquisa e na busca da autonomia intelectual diante do Estado e da Igreja.

Nesse sentido, desde os seus primórdios, a universidade, enquanto instituição, vem buscando conquistar a sua autonomia frente ao Estado e à Igreja, sendo que a história da universidade confunde-se com a sua luta pela conquista da autonomia acadêmica, didática, administrativa e de gestão.

\section{As Concepções Francesa, Alemã e Norte-americana de Universidade e a Sua Influência Sobre a Formação Universitária Brasileira}

Data da primeira metade do século XIX o surgimento dos dois modelos distintos de ensino superior - o alemão e o francês - que terão uma influência significativa sobre a concepção e a estrutura do ensino superior no Brasil.

$\mathrm{O}$ padrão francês napoleônico influenciou as universidades tradicionais da América Espanhola e inspirou a formação tardia das primeiras faculdades profissionais no Brasil, no século XIX. A universidade propriamente dita, no Brasil, se formou na primeira metade do século XX, sob influência dos modelos francês e alemão, como foi o caso da Universidade do Rio de Janeiro (URJ), criada em 1920 e da Universidade de São Paulo (USP), fundada em 1934, embora antes tivessem sido criadas universidades privadas efêmeras, tais como a de Manaus, surgida em 1909 e extinta em 1926, a de São Paulo, originada em 1911 e extinta em 1917 e a do Paraná, criada em 1912 e extinta em 1915. (CUNHA, 1986)

O ensino superior francês da primeira metade do século XIX apresenta uma grande singularidade em relação a todos os outros países europeus, na medida em que Napoleão aboliu as universidades pela Convenção do dia 15 de setembro de 1793. As universidades eram mal vistas pelos revolucionários franceses devido ao espírito corporativo quase medieval nelas existente e à ênfase na cultura clássica, que impedia a entrada das ciências experimentais 
e do enciclopedismo. Em síntese, a universidade francesa era vista como um “aparelho ideológico do Antigo Regime."

Nesse sentido, a primeira e principal idéia adotada para o ensino superior brasileiro, desde a chegada da Corte portuguesa ao Rio de Janeiro, foi a recusa da criação de uma universidade, havendo a fundação de faculdades isoladas. Essa posição foi assumida por muitos governantes brasileiros, fazendo com que a Assembléia Geral Legislativa deixasse de aprovar 42 projetos de criação de uma universidade no período imperial. (CUNHA, 1986, p. 137)

A influência francesa sobre a concepção organizacional (institucional) da educação superior brasileira pode ser detectada, sobretudo, no Rio de Janeiro, mais do que em São Paulo. Isto porque o modelo napoleônico de universidade, caracterizado por escolas isoladas de cunho profissionalizante, com dissociação entre ensino e pesquisa e grande centralização estatal, vai marcar profundamente a organização da Universidade do Rio de Janeiro. Não houve, como em São Paulo, a preocupação de introduzir a pesquisa como uma das principais finalidades da universidade, nem com a constituição de uma Faculdade de Filosofia, Ciências e Letras - entendida como coração da universidade, como centro integrador e catalisador da idéia de universidade, responsável pela ciência livre e desinteressada - características do modelo universitário alemão do século XIX, que influenciou a organização da USP.

Na França, somente sob a Terceira República, em 1896, reorganizaram-se algumas das escolas isoladas, primeiro constituindo-se um corpus de faculdades autárquicas e posteriormente - com o nome de universidade - uma federação de unidades independentes. Ficaram separados do conjunto a Escola Politécnica (voltada para a formação dos quadros técnicos), a Escola Normal Superior (destinada à formação dos educadores), o Colégio de França, o Instituto e o Museu de História Natural, aos quais se juntariam, muito mais recentemente, o Museu do Homem e o Centre National de la Recherche Scientifique (CNRS) (RIBEIRO, 1975, p. 52-53). Nesse sentido, criou-se uma hierarquia entre as "grandes escolas", voltadas para a pesquisa científica e para a formação de alto nível das elites intelectuais, e as universidades, responsáveis por um ensino mais massificado, sendo a pesquisa concentrada, portanto, fora das universidades.

Fato semelhante ocorrerá no Rio de Janeiro, quando das primeiras décadas de funcionamento da Universidade do Rio de Janeiro, constituída de faculdades profissionalizantes, que tinham como enfoque o ensino e não a pesquisa. Paralelamente, nas décadas de 30, 40 e 50, assistimos à proliferação de institutos extra-universitários ou para-universitários de pesquisa na então Capital do país, com acentuada dissociação entre ensino universitário e pesquisa científica. 
As Faculdades de Filosofia, Ciências e Letras que, nas universidades alemãs, representavam o órgão universitário por excelência, integrador das demais atividades e fonte de pesquisas inovadoras, na França não preencheram essa função, situando-se na hierarquia científica abaixo das escolas especializadas. Isto verifica-se em vários níveis: nos custos e na duração maior dos estudos de Direito e Medicina, por exemplo, em relação aos das faculdades de Letras e Ciências; nas origens sociais dos estudantes, provenientes das classes menos favorecidas, no caso destas últimas; e nos salários dos docentes, maiores e mais compensadores no caso das faculdades profissionais. (CHARLE; VERGER, 1996, p. 78-79)

Mais uma vez, aqui encontramos uma proximidade entre a estrutura da universidade francesa e a da URJ, que ao contrário da USP, não possuía uma Faculdade de Filosofia, Ciências e Letras nos moldes aproximativos do modelo alemão. A Faculdade Nacional de Filosofia, Ciências e Letras da URJ, instituída pela Lei $n^{\circ} 452$ de 1937, sempre caracterizou-se pelo enfoque no ensino profissionalizante, sem o desenvolvimento de uma tradição em pesquisa na área de humanidades, não exercendo o papel de órgão integrador por excelência das atividades universitárias.

O caráter fragmentado e profissionalizante das instituições brasileiras de ensino superior vinha recebendo críticas desde a época imperial, críticas estas que se dirigiram às primeiras universidades criadas no século $\mathrm{XX}$, como a do Rio de Janeiro. Em 1926, Fernando de Azevedo, um dos principais idealizadores da USP, defendia a idéia de integração da instituição universitária, com ultrapassagem da mera formação especializada e profissional, através da criação da Faculdade de Filosofia, Ciências e Letras (FFCL). Ele denunciava a insuficiência das escolas profissionais, meras transmissoras de um saber não superior porque estritamente especializado e comprometido com aplicações imediatas. Defendia o cultivo de um saber livre e desinteressado, capaz de contribuir para o progresso da nacionalidade em formação e para o enriquecimento da educação. Somente uma universidade que cultivasse esses valores poderia ser eficaz na formação das novas elites dirigentes. A FFCL seria o local onde se desenvolveriam os estudos de cultura livre e desinteressada. Ela seria o locus do curso básico, preparatório para todas as escolas profissionais.

Dos modelos de universidade instituídos a partir do século XVIII na Europa, o que mais se assemelha a esta concepção de universidade como formadora de elites dirigentes com base na constituição de uma Faculdade de Filosofia, Ciências e Letras como órgão central do ensino superior e com conseqüente ênfase na formação científica de cunho humanista, não-pragmático, é o modelo alemão. 
Encontramos várias aproximações entre a concepção alemã e a paulista de universidade, na época de sua fundação: preocupação fundamental com a pesquisa e com a unidade entre ensino e investigação científica; ênfase na formação geral e humanista, ao invés da formação meramente profissional; autonomia relativa da universidade diante do Estado e dos poderes políticos; concepção idealista e não-pragmática de universidade, em detrimento da concepção de universidade como prestadora de serviços ao mercado e à sociedade; fraco vínculo entre intelectuais e poder político, ou seja, ligação não-imediata entre intelligentzia e poder; concepção liberal e elitista de universidade; estreita ligação entre a formação das elites dirigentes e a questão da nacionalidade. (PAULA, 2002b)

A criação da Universidade de Berlim, em 1810, representou um marco fundamental para a concepção moderna de universidade. Foi precedida por uma reflexão teórica da qual fizeram parte filósofos, como Fitche, Schelling e Schleiermacher e filólogos, com Wolf e Guillermo de Humboldt, o verdadeiro fundador da Universidade de Berlim. Em seu texto de 1810, intitulado Sobre a organização interna e externa dos estabelecimentos cientificos superiores em Berlim, Humboldt (1959) destaca a importância da pesquisa como função primordial da universidade, ao lado do ensino, concebendo a indissociabilidade do ensino, da pesquisa e da formação como característica essencial da Universidade, ao lado da universalidade de campos de conhecimento, garantida pela centralidade do papel desempenhado pela Faculdade de Filosofia, Ciências e Letras como órgão articulador, por excelência, dos diversos campos do saber. Além disto, Humboldt, em seus escritos, concebe o trabalho científico como livre de quaisquer tipos de injunções e pressões, tais como do Estado, da Igreja e de outras demandas externas ao campo acadêmico universitário.

Segundo a concepção alemã do século XIX, para que a universidade desempenhe plenamente o seu papel, ela deve ser autônoma, embora a sua existência dependa economicamente do Estado. Nesse sentido, num Estado que limite a liberdade de ensino e de pesquisa, que impeça a busca e a transmissão incessante da verdade científica, não será possível a existência de uma autêntica universidade. Ainda segundo esta concepção, existe uma preocupação fundamental com a formação integral e humanista do homem, ao invés da formação meramente profissional, voltada para o mercado de trabalho.

Encontramos acentuadas divergências entre as concepções alemã e francesa de universidade. O modelo alemão enfatiza a importância da pesquisa na universidade, e mais do que isto, da indissociabilidade entre ensino, pesquisa e formação; ao passo que, no modelo francês, a pesquisa não é tarefa primordial 
da universidade, havendo dissociação entre universidades, que se dedicam fundamentalmente ao ensino, e "grandes escolas", voltadas para a pesquisa e a formação profissional de alto nível. Enquanto o modelo francês volta-se para a formação especializada e profissionalizante, via escolas isoladas; o alemão enfatiza a formação geral, científica e humanista, com enfoque na totalidade e universalidade do saber e na conseqüente importância da Faculdade de Filosofia, Ciências e Letras como órgão central da universidade. Enquanto a universidade francesa, desde Napoleão, é mantida e dirigida pelo Estado, tornando-se uma espécie de aparelho ideológico deste, com pequena autonomia frente aos poderes políticos; a universidade alemã, embora sendo instituição do Estado, por ele mantida financeiramente, conservou uma parte notável do seu caráter corporativo e deliberativo, gozando de liberdade de ensino e de pesquisa, nas suas primeiras décadas de funcionamento, no século XIX. Enquanto a intelligentzia francesa possuía forte vínculo com o Estado e com a política napoleônica, os intelectuais alemães mantinham uma posição de maior independência frente aos poderes políticos instituídos.

Apesar das diferenças existentes entre a concepção francesa e a alemã, em ambas houve a preocupação com a questão nacional, ou seja, com a afirmação da nacionalidade. No primeiro caso, esta preocupação conduziu a uma visão mais pragmática de universidade, voltada para os problemas econômicos, políticos e sociais emergentes, numa chave autoritária (de grande centralização e controle estatais). Aqui, mais uma vez, podemos estabelecer uma correlação entre o caso francês e o carioca, nas suas origens. No modelo alemão, a preocupação com a constituição da nacionalidade se deu numa chave liberal-elitista, com maior autonomia da universidade diante do Estado, desembocando numa concepção mais idealista e acadêmica, e menos pragmática de universidade. Estas características podem ser encontradas no discurso e nas propostas dos fundadores da USP. (PAULA, 2002b)

No caso brasileiro, poderíamos dizer que a URJ teve forte influência do modelo francês, pois, desde a sua criação, teve um cunho fundamentalmente profissionalizante, que desenvolveu por décadas, estando muito próxima do Estado e mantendo com ele uma relação de cumplicidade; a USP sofreu influência das concepções francesa e alemã, pois esta universidade já nasceu, conjuntamente com a sua Faculdade de Filosofia, Ciências e Letras, voltando-se não apenas para o ensino, mas também para a pesquisa, e buscando autonomia intelectual diante da Igreja e do Estado. (PAULA, 2002b)

A partir de fins da década de 1950, a universidade brasileira começa a sofrer muitas críticas. Governo e comunidade acadêmica se mobilizam na direção 
da sua reformulação. Com o golpe de 1964, as reivindicações do movimento estudantil e dos professores mais progressistas, identificados com a reformulação estrutural da universidade e da sociedade brasileiras, foram distorcidas e absorvidas pelos técnicos do MEC e pelos consultores norte-americanos que os auxiliaram a reformar as nossas universidades. Após os Acordos MEC/USAID, respectivamente de 1965 e 1967, e do Relatório Atcon, de 1966, a influência norte-americana sobre a universidade brasileira se faz sentir de forma mais acentuada.

Nesse sentido, a concepção norte-americana influenciou não apenas as universidades européias, como a alemã, mas também as universidades latinoamericanas, como as brasileiras. No Brasil, esta concepção será amplamente difundida a partir da Reforma Universitária de 68, atingindo a estrutura organizacional e as finalidades de todas as universidades.

Assim é, que a Lei 5540, responsável pela Reforma de 1968, incorporou várias características da concepção universitária norte-americana, a saber:

a) vínculo linear entre educação e desenvolvimento econômico, entre educação e mercado de trabalho;

b) estímulo às parcerias entre universidade e setor produtivo;

c) instituição do vestibular unificado, do ciclo básico ou primeiro ciclo geral, dos cursos de curta duração, do regime de créditos e matrícula por disciplinas, todas estas medidas visando uma maior racionalização para as universidades;

d) fim da cátedra e incorporação do sistema departamental;

e) criação da carreira docente aberta e do regime de dedicação exclusiva;

f) expansão do ensino superior, através da ampliação do número de vagas nas universidades públicas e da proliferação de instituições privadas, o que provocou uma massificação desse nível de ensino;

g) a idéia moderna de extensão universitária;

h) ênfase nas dimensões técnica e administrativa do processo de reformulação da educação superior, no sentido da despolitização da mesma. (PAULA, 2002a)

A idéia de racionalização foi o princípio básico da Reforma de 68 , dela derivando as demais diretrizes, todas embasadas em categorias próprias da linguagem tecnicista e empresarial: eficiência, eficácia, produtividade, etc. Isto 
porque o processo educacional foi associado à produção de uma mercadoria que, como todo processo econômico, implicava em um custo e um benefício.

No modelo norte-americano, a instituição universitária procura associar estreitamente os aspectos ideais (ensino e pesquisa) aos funcionais (serviços), estruturando-se de tal maneira que possa ajustar-se às necessidades da massificação da educação superior e da sociedade de consumo. Ao adotar a forma empresarial, boa parte das universidades procura atender aos interesses imediatos do setor produtivo, do Estado e da sociedade, produzindo especialistas, conhecimento tecnológico e aplicado, pesquisas de interesse utilitário, assim como serviços de uma maneira geral. O ideal da concepção alemã de universidade, voltada para a formação humanista, integral e "desinteressada" do homem, tendo como base uma Faculdade de Filosofia, Ciências e Letras, é crescentemente substituído pela racionalização instrumental e pela fragmentação do trabalho intelectual.

O importante a ser ressaltado é que a busca de uma maior racionalidade instrumental para as universidades, sobretudo as públicas, ressurge no cenário brasileiro com mais força a partir da década de 1980, num novo contexto político, econômico e social. As universidades públicas, no contexto do neoliberalismo, são acusadas pelos governos de "improdutivas", sendo permanentemente impelidas a prestarem conta de sua "produtividade", no âmbito do ensino, da pesquisa e da extensão. Para tal, desenvolvem-se mecanismos de avaliação da "produtividade" docente, departamental e institucional, nos níveis da graduação e da pós-graduação; tenta-se inserir as universidades na lógica racionalizadora do capital, vinculando-as ao mercado, já que o Estado se desobriga cada vez mais do financiamento destas instituições. (PAULA, 2002a)

No contexto neoliberal, marcado pela razão instrumental mercadológica do capital, a concepção norte-americana, com seu conteúdo pragmático e utilitário, torna-se hegemônica nas instituições de educação superior brasileiras. Há um processo crescente de "macdonaldização" do ensino, sobretudo no âmbito das instituições privadas, com a proliferação de cursos que, no passado, não possuíam o menor status acadêmico, havendo uma banalização e um aligeiramento da formação em nível superior para atender as demandas de mercado e dos "clientes" que procuram um título universitário.

\section{A Formação Universitária no Contexto Neoliberal}

A universidade brasileira, sobretudo a partir dos anos 1990, tem recebido forte influência das políticas neoliberais e dos organismos internacionais do 
capital, tais como FMI, Banco Mundial, Organização Mundial do Comércio, dentre outros, sofrendo pressões transnacionais num cenário de globalização excludente. Da internacionalização da educação superior passamos ao comércio dos serviços educacionais. Ou seja, a educação superior deixou de ser vista como dever de Estado e direito do cidadão, sendo concebida como serviço, mercadoria, e perdendo, com isto, o seu caráter eminentemente público. Neste cenário, ganharam destaque os contratos de gestão, as parcerias públicoprivadas, a diversidade de fontes de financiamento para a educação superior. Neste contexto, deu-se um vazio de Estado no financiamento das instituições públicas de educação superior, o que provocou, por um lado, a proliferação indiscriminada de instituições privadas de ensino superior (temos, hoje, um dos índices mais altos de privatização da educação superior na América Latina e no mundo - cerca de $90 \%$ das instituições brasileiras de ensino superior são privadas, sendo responsáveis por $70 \%$ das matrículas neste nível de ensino) e por outro, a privatização interna do ensino, da pesquisa e da extensão nas universidades públicas.

A política neoliberal do Estado para as universidades brasileiras, iniciada na segunda metade da década de 1980 e aprofundada pelos governos Fernando Collor e Fernando Henrique Cardoso, apresentou como características um desinvestimento do Estado no campo da pesquisa científica e tecnológica e um abandono em relação ao ensino universitário público, sobretudo de graduação, base da formação superior. Paradoxalmente, verificou-se uma crescente intervenção do Estado e do MEC nas universidades, via sistema de avaliação e outras medidas autoritárias, ferindo a autonomia das instituições universitárias, inscrita no artigo 207 da Constituição Federal de 1988. (PAULA, 2003)

Acentuaram-se o aligeiramento e a fragmentação do processo de formação, através dos cursos de curta duração, cursos seqüenciais, cursos politécnicos, cursos de educação a distância, mestrados profissionais, etc, muitas dessas medidas instituídas pela Lei de Diretrizes e Bases da Educação, no 9.394, de 1996.

Dentro deste quadro, acentuou-se o processo de privatização crescente do ensino, da pesquisa e da extensão nas universidades públicas, através, sobretudo, dos cursos de pós-graduação "autofinanciáveis", na verdade pagos pelos estudantes, das pesquisas encomendadas por empresas e dos serviços prestados e cobrados à sociedade de mercado, desfigurando o conceito de extensão como forma de socialização de conhecimentos e práticas da universidade para a sociedade. O que significa, em última instância, a privatização, dentro e a partir das instituições públicas, de um conhecimento socialmente produzido pela comunidade acadêmica. (PAULA; AZEVEDO, 2006) 
A reforma proposta pelos governos de Fernando Henrique Cardoso para as universidades brasileiras, sobretudo para o sistema federal, fez parte de um projeto maior de reforma do Estado. Foi proposta a modernização da máquina estatal, no sentido de um melhor aproveitamento dos recursos disponíveis, para que se evitasse o "desperdício". O Plano Diretor da Reforma do Aparelho do Estado, formulado em 1995 pelo Ministério da Administração Federal e Reforma do Estado (BRASIL/MARE), abriu mais um precedente para a privatização das universidades públicas. Luiz Carlos Bresser Pereira, quando foi Ministro do MARE, propôs a transformação das instituições de serviços do Estado, como é considerado o caso das universidades federais, em "organizações sociais públicas não-estatais". Esta categoria foi concebida para contemplar as instituições que desempenham as chamadas “atividades competitivas.” Aplicou-se a concepção da eficiência gerencial pela competitividade máxima. O mecanismo proposto foi o Contrato de Gestão, que conduziria à captação de recursos privados como forma de reduzir os investimentos públicos no ensino superior.

O interessante a ser observado é que estas medidas, típicas de um Estado neoliberal, reatualizaram muitas das medidas propostas para o ensino superior à época da Reforma Universitária de 1968, quando estava no poder o Estado autoritário militar. As propostas “modernizantes” para a universidade, na década de 1960, que partiam do consultor naturalizado norte-americano Rudolph Atcon, do General-de-Brigada Carlos de Meira Mattos, dos acordos MEC/USAID, e que foram incorporadas ao relatório do Grupo de Trabalho que elaborou a Reforma, viam a educação como instrumento de aceleração do desenvolvimento, devendo a universidade estar a serviço do sistema produtivo; propunham a "racionalização" da instituição universitária, com relação aos recursos financeiros, materiais e humanos; buscavam uma maior "produtividade e eficácia" para o sistema universitário, devendo a universidade funcionar como uma empresa privada; propunham um maior entrosamento entre as universidades e o setor produtivo, inclusive como forma de captação de recursos adicionais; e recomendavam a cobrança de anuidades/mensalidades nas instituições universitárias públicas como forma de justiça social. (PAULA, 2002a)

Uma das diferenças fundamentais entre as medidas adotadas pelos governos autoritários militares e pelos recentes governos neoliberais reside num maior investimento na educação superior por parte dos primeiros, o que possibilitou a expansão do sistema como um todo, nas décadas de 60 e 70. Foi neste contexto que o nosso sistema de pós-graduação desenvolveu-se, tornando-se o mais abrangente da América Latina e qualificando os nossos mestres e doutores com padrões de excelência. Muitas universidades brasileiras, particularmente as 
públicas, alcançaram padrões internacionais de qualidade. Somos referência entre os países em desenvolvimento na área de pesquisa e pós-graduação no país e no exterior, graças a uma política de Estado executada com rigor via agências de fomento à pesquisa, como CAPES e CNPq, ao longo de várias décadas.

Poderíamos dizer que existe um fosso, hoje, nas universidades, entre a graduação e a pós-graduação stricto sensu. A universidade da graduação imagina-se pública, grande e quer receber mais estudantes e se democratizar. A universidade da pós-graduação, da CAPES e do CNPq, imagina-se pequena e de elite, tornando-se cada vez mais seletiva. Este quadro marca a crise e a fragmentação da instituição universitária, na atualidade, o que demonstra nitidamente a ausência de identidade da universidade brasileira no contexto do neoliberalismo. (PAULA, 2003)

Esta fragmentação gera várias segregações e hierarquias, tais como entre graduação e pós-graduação, professores e pesquisadores, professores e prestadores de serviços, entre cursos de longa duração e de curta duração, cursos gratuitos e pagos, cursos valorizados socialmente e no âmbito do mercado de trabalho e cursos pouco valorizados socialmente e no mercado de trabalho, entre uma formação mais sólida e uma formação mais aligeirada, dentre outras.

Os argumentos em prol da diversificação do ensino superior brasileiro têm crescido cada vez mais, fazendo parte da atual política para esse nível de ensino. Alega-se que a diversificação das instituições de ensino superior - que rompe com o pressuposto da indissociabilidade entre ensino, pesquisa e extensão e com a universalidade de campos do saber como características que dão identidade às universidades - é pré-requisito para o atendimento de demandas diversas por ensino superior e para a democratização deste nível de ensino. Defende-se a existência de instituições "universitárias" que ocupam-se apenas do ensino profissionalizante, sem preocupação com uma formação integral do estudante, o que representa um golpe no conceito tradicional de universidade enquanto instituição que alia ensino e pesquisa de alto nível, dedicando-se à pluralidade de campos do conhecimento e permitindo uma formação no sentido amplo do termo; ao lado da defesa dos "escolões" de terceiro grau, assistimos hoje a defesa e o retorno dos cursos “universitários” aligeirados, de curta duração, tão questionados e criticados no passado, que ressurgem com uma nova roupagem (cursos seqüenciais, cursos politécnicos, etc). Essas iniciativas têm como intenção oferecer alternativas mais acessíveis e menos custosas (em termos de tempo, dinheiro, investimento intelectual) aos "clientes" que procuram o ensino superior. Além de uma banalização crescente e de uma diluição do sentido da formação universitária, essas medidas acabam por produzir uma nova divisão 
no campo universitário e dos "clientes" que procuram pelo ensino superior: de um lado, instituições de excelência que aliam ensino e pesquisa de alto nível, mais procuradas pelas elites dominantes, de outro lado, instituições de ensino técnico e profissionalizante de terceiro grau, mais procuradas pelos estudantes com menor capital social e cultural. Dentro de uma mesma instituição universitária, os alunos com menor capital social e cultural, em geral, dirigem-se para os cursos aligeirados, que exigem menos investimento material e cultural, enquanto que as elites dominantes continuam chegando em maior quantidade aos cursos que dão mais status profissional, que exigem um acúmulo maior de capital social e cultural. Isto demonstra que essas iniciativas, ao invés de contribuírem para democratizar o ensino superior, na verdade, apenas reproduzem e reforçam as desigualdades sociais do sistema capitalista.

Dentro desta ótica, devem ser analisadas algumas das políticas propostas para a educação superior no Governo Lula: democratização do acesso pela via privada, através de vultosas somas de isenção fiscal para as instituições privadas, com ensino de qualidade duvidosa para os estudantes carentes - PROUNI - medida provisória n. 213, de 10 de setembro de 2004 (PAULA, 2006); elevação, num prazo de 5 anos, da taxa média de conclusão dos cursos presenciais de graduação para $90 \%$, praticamente dobrando a relação de alunos de graduação por professores em cursos presenciais, com precarização das condições de ensino - REUNI - Decreto n. 6.096, de 24/04/2007; precarização das condições de trabalho dos professores nas universidades federais - banco de professores equivalentes - Portaria Interministerial MEC/MPOG n. 22, de 24/04/2007, enfraquecendo a pesquisa e a extensão nas universidades federais; projeto Universidade Nova (ALMEIDA FILHO, 2007), incorporado pelo REUNI, que propõe a "diversificação das modalidades de graduação, preferencialmente não voltadas à profissionalização precoce e especializada" (item IV do artigo $2^{\circ}$ do REUNI), visando o rearranjo da arquitetura curricular dos cursos de graduação com base no Processo de Bolonha europeu e no modelo dos Colleges norteamericanos (Bacharelados Interdisciplinares), esvaziando a profissionalização, empurrada para o segundo ciclo universitário; na linha do aligeiramento da formação deve ser analisada, também, a proposta de “democratização" do acesso ao ensino superior via educação a distância, tão defendida pelo Governo Lula. Todas estas medidas servirão de índices e estatísticas para este governo dizer que, ao final de 8 anos, democratizou o acesso à educação superior, colocando mais estudantes neste nível de ensino, sem priorizar a garantia da sua qualidade e da formação oferecida. 
A universidade brasileira é uma instituição jovem em termos latino-americanos e mundiais, nasceu associada aos desafios republicanos do Brasil moderno. Contudo, carrega uma enorme responsabilidade: contribuir para a formação de cidadãos críticos e participativos, pessoas que ajudarão a construir um Brasil mais desenvolvido, justo e democrático. Para tal, é preciso democratizar-se pela via pública, com garantia de uma formação de qualidade, em todas as áreas do conhecimento, sem apelo a cursos aligeirados que servirão apenas para o alcance de estatísticas esvaziadas de efetivo conteúdo formativo.

\section{Referências}

ALMEIDA FILHO, Naomar de. Universidade nova: textos críticos e esperançosos. Brasília: UnB, 2007.

BRASIL, Congresso Nacional. Projeto de lei 7.200/2006: reforma da educação superior. Estabelece normas gerais da educação superior, regula a educação superior no sistema federal de ensino, altera as Leis n. 9.394/96, 8.958/94, 9.504/97, 9.532/97, 9.870/99 e dá outras providências.

BRASIL. Atos do Poder Executivo. Decreto n. 6.096, de 24 de abril de 2007. Institui o Programa de Apoio a Planos de Reestruturação e Expansão das Universidades Federais - REUNI, Diário Oficial da União, Brasília, 2007.

BRASIL/MARE (Ministério da Administração e Reforma do Estado). Plano Diretor de Reforma de Aparelho de Estado. Brasília: Presidência da República, Câmara de Reforma do Estado, Ministério da Administração Federal e Reforma do Estado, 1995.

BRASIL. MEC/MPOG ( Ministério da Educação e Cultura/ Ministério do Planejamento, Orçamento e Gestão). Portaria Interministerial n. 22, de 24/04/2007. Institui um banco de professores-equivalentes nas universidades federais, Brasília, 2007.

CHARLE, Christophe; VERGER, Jacques. História das universidades. São Paulo: Editora da UNESP, 1996.

CUNHA, Luiz Antônio. A universidade temporã: da colônia à era de Vargas. 2. ed. Rio de Janeiro: Livraria Francisco Alves, 1986. 
HUMBOLDT, Guillermo. Sobre a organização interna e externa dos estabelecimentos científicos superiores em Berlim. In: LA IDEA de la universidad en Alemania. Buenos Aires: Editorial Sudamericana, 1959.

PAULA, Maria de Fátima. A modernização da universidade e a transformação da intelligentzia universitária. Florianópolis: Insular, 2002a.

. USP e UFRJ. A influência das concepções alemã e francesa em suas fundações. Tempo Social, São Paulo, v. 14, n. 2, p. 147-161, out. 2002 b.

A perda da identidade e da autonomia da universidade brasileira no contexto do neoliberalismo. Avaliação, Campinas; Sorocaba, v. 8, n. 4, p. 5367, dez. 2003.

. A reforma universitária do Governo Lula no contexto das políticas neoliberais. In: PAULA, Maria de Fátima (Org.). Debatendo a universidade: subsídios para a reforma universitária. Florianópolis: Insular, 2004.

- As propostas de democratização do acesso ao ensino superior do Governo Lula: reflexões para o debate. Avaliação, Campinas, v. 11, n. 1, p. 133-147, mar. 2006.

PAULA, Maria de Fátima; AZEVEDO, Marcela Davino. Políticas e práticas de privatização do público na universidade: o caso UFF. Avaliação, Campinas, v. 11, n. 3, p. 91-111, set. 2006.

RIBEIRO, Darcy. A universidade necessária. 2. ed. Rio de Janeiro: Paz e Terra, 1975. 